
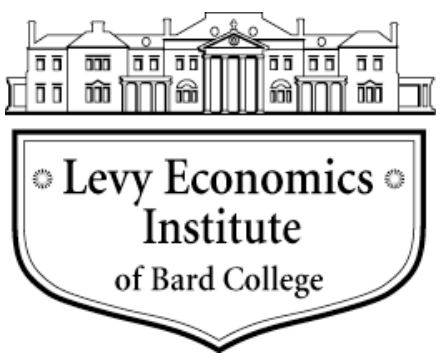

Working Paper No. 785

\title{
Integrating Time in Public Policy: Empirical Description of Gender-specific Outcomes and Budgeting
}

by

\author{
Lekha Chakraborty* \\ Levy Economics Institute of Bard College
}

January 2014

*Contact: lekhachakraborty@gmail.com

The Levy Economics Institute Working Paper Collection presents research in progress by Levy Institute scholars and conference participants. The purpose of the series is to disseminate ideas to and elicit comments from academics and professionals.

Levy Economics Institute of Bard College, founded in 1986, is a nonprofit, nonpartisan, independently funded research organization devoted to public service. Through scholarship and economic research it generates viable, effective public policy responses to important economic problems that profoundly affect the quality of life in the United States and abroad.

Levy Economics Institute

P.O. Box 5000

Annandale-on-Hudson, NY 12504-5000

http://www.levyinstitute.org

Copyright (C) Levy Economics Institute 2014 All rights reserved

ISSN 1547-366X 


\begin{abstract}
Incorporating time in public policymaking is an elusive area of research. Despite the fact that gender budgeting is emerging as a significant tool to analyze the socioeconomic impacts of fiscal policies and thus identify their impacts on gender equity, the integration of time-use statistics in this process remains incomplete, or is even entirely absent, in most countries. If gender budgeting is predominantly based on the index-based empirical description of genderspecific outcomes, a reexamination of the construction of the gender (inequality) index is needed. This is necessary if we are to avoid an incomplete description of the gender-specific outcomes in budget policymaking. Further, "hard-to-price" services are hardly analyzed in public policymaking. This issue is all the more revealing, as the available gender-inequality index - based on health, empowerment, and labor market participation - so far has not integrated time-use statistics in its calculations. From a public finance perspective, the gender budgeting process often rests on the assumption that mainstream expenditures, such as public infrastructure, are nonrival in nature, and that applying a gender lens to these expenditures is not feasible. This argument is refuted by time budget statistics. The time budget data reveal that this argument is often flawed, as there is an intrinsic gender dimension to nonrival expenditures.
\end{abstract}

Keywords: Unpaid Care Work; Fiscal Policy; Gender Budgeting; Time Use; Macro Policy JEL Classifications: D13, J22, H31 
Integrating time in macro policy making remains an elusive area of research. Data paucity is often cited as the major constraint in undertaking such research, which is especially relevant for policy making related to non-monetized sectors. These sectors are often regarded as "hard-toprice" sectors and evade policy analysis. Time use statistics to a great extent solve the problems of non-monetized sectors by providing better workforce participation estimates for both the paid and unpaid sectors, as well as by removing the statistical invisibility of unpaid care work. However, despite the fact that gender budgeting is emerging as a significant socio-economic tool to analyze budgetary policies and to identify their effects on gender equity, the integration of time use statistics into this process remains partial or even nil across countries. It is interesting to recall that Gary Becker (1965), in a paper titled "A Theory of Allocation of Time", published in the Economic Journal, noted,

"throughout history the amount of time spent at work has never consistently been much greater than that spent at other activities. Economic development has led to a large secular decline in the work week so that today time spent at work is less than a third of the total time available.

Consequently, the allocation and efficiency of 'nonworking' time may now be more important to economic welfare than that of working time. Yet the attention paid by economists to the latter dwarfs any paid to the former."

The prime reason for the lack of integrating time budgets into gender budgeting is threefold. One, the time use survey itself is not conducted at a macro level in many countries. Though conducted in a few countries, those studies remain as one-point surveys and lack time series data. Two, the process of gender budgeting itself is highly partial across countries focusing broadly on the market economy and does not incorporate the analysis of unpaid care economy. Though the conceptual discussions of gender budgeting highlight the significance of giving attention to the statistical invisibility of the unpaid care economy in framing the policies related to gender budgeting, it is seldom translated to an empirical level. Three, gender budgeting is conducted across countries based on a highly restricted assumption that "all public expenditure cannot be gender partitioned," especially mainstream infrastructure spending (both social and physical). This assumption is highly controversial.

Even mainstream public expenditure - especially social and physical infrastructure - has gender differential impacts. The results of limited Benefit Incidence Analysis (BIA) conducted across income quintiles clearly show the distributional impacts of public expenditure across class and gender. However, BIA exercises are not carried out for certain public expenditures due 
to the lack of data on "units utilized." The time use budget is a significant domain of "unit utilized data" which is hardly used by any researchers engaged in BIA.

Gender budgeting has three significant components: (1) an empirical description of gender-specific outcomes; (2) analyzing the contribution of women not only in the market economy, but also in the unpaid care economy, and (3) analyzing budgets for the gender differential impacts of public expenditure. Time use statistics play a significant role in each of these components, which is highly neglected in the studies on gender budgeting. This paper takes up these issues and analyses the scope and limitations of integrating time use in gender budgeting.

The paper is organized as follows. Section I explains gender budgeting and its rationale. Section II deals with the analytical framework of gender budgeting, incorporating time budgets. Section III discusses the scope of time use statistics in the empirical description of genderspecific outcomes. Section IV highlights the significance of time use in removing the statistical invisibility of unpaid care sector and integrating this information in gender budgeting. Section V focuses on the use of time budgets in analyzing the gender differential impacts of public expenditure. Section VI concludes.

\section{GENDER BUDGETING AND ITS RATIONALE}

Gender budgeting is an innovation that translates gender-specific commitments into budgetary commitments. It is not about making a budget exclusively for women, nor is it earmarking functional finance for programs targeting women. It is a means to analyze the entire budget through a gender lens in order to identify the gender differential impacts of the budgetary process. Culture affects the socio-economic outcomes of fiscal policies. Prima facie, budgets may appear to be gender neutral. However the asymmetry in the socially determined systemic roles played by men and women can lead to differential budget impacts based on gender. Gender budgeting is one of the ways to unpack the "social" content of the macro policies and to get public policies right in terms of gender sensitive human development ${ }^{1}$.

Broadly speaking, budgeting involves four components: (1) resource allocation of resources to various heads (i.e., budget accounts or line items), (2) the actual public outlays on

\footnotetext{
${ }^{1}$ For the conceptual and empirical analysis of gender budgeting including India, refer Elson (1995), Elson and Cagatay (2000), Stotsky, J (2006), Lahiri, A et al (2000, 2001, 2000a,b, 2002), Rao and Chakraborty (2006), Chakraborty and Bagchi (2007), Chakraborty (2002,2003, 2005, 2006, 2007, 2009, 2011).
} 
various heads, (3) an accounting of how public resources are spent for a particular purpose (including fiscal marksmanship), and (4) an analysis of the effectiveness of the public spending in delivering the intended results. Gender budgets examine these four components through a gender lens.

Can all public spending be gender partitioned? While it is a debate as to whether public goods and services, which are non-rival and non-excludable in nature (e.g., defense) are amenable to gender partitioning, many other public expenditures have gender differential impacts. It is all the more relevant to note that the treatment of non-rival and non-excludable goods and services are issues not just for gender, but also for other disadvantaged sections of the population like Aboriginals, which cannot be segregated on a "geographic area" basis. Yet another point to be noted is that the public expenditure on infrastructure, such as roads, irrigation, energy, water and sanitation, science and technology etc., has intrinsic gender dimensions. It is also important to examine the infrastructure budgets such as energy, technology and transport that are assumed to be "gender-neutral." An analysis of infrastructure budgets not only reveals the differing needs of and constraints on women's and men's lives and productive roles, but would also help to reveal the inefficiency of existing allocations which may not be adequately reaching women and men. An International Food Policy Research Institute (IFPRI) study showed that public expenditure on road infrastructure has the largest impact on poverty reduction (Fan, Hazell and Thorat, 1999). This generates debate on "specifically targeted programs for the poor" versus "infrastructure programs," particularly in terms of gender budgeting.

Yet another example is that public spending to augment the supply of safe drinking water can benefit women, more than men, in the care economy by cutting down on the time spent fetching water from rivers or ponds. The existing practice of budgeting across countries may not pay any special attention to the impact of budgets on women in the care economy. The System of National Accounts 1993 recognises unpaid work in the care economy as "productive" and as "work," however it is left outside the purview of the calculation of GDP and kept as satellite accounts. The point to be noted is that despite the recognition of the care economy by System of National Accounts (SNA) in 1993, policy makers and economists have not yet satisfactorily integrated the care economy into macro policy planning.

In many ways, government budgets are "subsidized" by work performed in the unpaid care economy. For instance, when a government cuts back public expenditure on health, it is 
women (caregivers) in households who bear the brunt of the cut. Yet another example is that to cope with the increasing demand for services generated by HIV/AIDS, many countries are opting for home-based care systems, where volunteer or low paid caregivers provide care to the patients rather than patients being cared for in hospitals. This can reduce the public expenditure on health by a considerable amount. However, the point to be noted is that when a public expenditure policy on health is designed in any country, policy makers take into consideration only the "users" of health services, not the health providers (i.e., the caregivers at household level). The implications of this example for gender budgeting are tremendous.

\section{ANALYTICAL FRAMEWORK OF GENDER BUDGETING INCORPORATING TIME BUDGETS}

The analytical framework for gender budgeting can be dichotomized into: (a) ex-post gender budgeting in which the existing budget is analyzed through a gender lens; and (b) ex-ante gender budgeting in which the needs of the women are identified first and then included in the budget process. Ex-ante budgeting is basically what we aim for in terms of gender budgeting; while ex-post focuses on a gender analysis of existing budgets. Time use statistics have a significant part in both the ex-ante and ex-post gender budgeting analysis. In an ex-post analysis of gender budgeting, the analysis of mainstream expenditures (using the assumption that all public spending has gender differential impacts) can use time budgets to show gender differential effects of public spending. In ex-ante gender budgeting, the identification of gender specific needs and preferences before budgeting extracts data on revealed preferences and demand mechanisms based on the time use statistics.

\section{II.1. Ex-post}

Ex-post analysis begins with the identification of three categories of public expenditure: (1) specifically targeted expenditure to women and girls (100 percent targeted for women), (2) prowomen allocations, which are the composite expenditure schemes with as a women component (that is, a scale of $100>$ exp. $\geq 30$; at least 30 percent targeted for women), and (3) residual public expenditures that have gender-differential impacts (that is, a scale of $0 \geq \exp$. $>30$ ). It is relatively easy to identify the programs specifically targeting women across ministries from the Expenditure Budget documents. But the challenge is that the information specific to women contained in the composite programs is not readily available in the budget documents. Attempts 
to incorporate time use in ex-post gender budgeting belong to second and third categories. Across the globe, particularly in India, only a limited number of the Demand for Grants in the second and third categories are analyzed through a gender lens due to the lack of unit utilized data on public provisioning. The point that should be highlighted here is that time budgets provide a rare gamut of data on units utilized. Illustrations of this point are provided later in this paper.

Ex-post analysis can integrate the methodology of gender disaggregated benefit incidence analysis. Benefit incidence analysis estimates the distributional impacts of public expenditures across different demographic and socioeconomic groups. It involves allocating unit cost according to individual utilization rates of public services. It can identify how well public services are targeted to certain groups in the population, across gender, income quintiles, and geographical units. However, BIA studies have been largely confined to education and health sectors due to the comparative richness of unit utilized data from the secondary sources (Demery, 2000), Demery et al., (1995), Mahal et al., (2001), and Chakraborty et al., (2013). To analyze the distributional impact of public expenditures on water supply and energy is a difficult undertaking at the macro level due to the paucity of data on units utilized. The point to be noted here is that time use statistics may provide the data on the units utilized for other social sector expenditures. Chakraborty (2008a, 2008b, 2010) attempted an illustrative gender disaggregated benefit incidence analysis of the water sector in India using time use data.

\section{II.2. Ex-ante}

The ex-ante process implements the goal of analyzing gender equity in an iterative manner as follows: (1) identifying the spatial gender issues, (2) translating the gender concerns into relevant objectives to be included in the budget policy/programs, (3) redefining the gender strategies at the policy and program levels with targets, (4) defining the gender related performance indicators, and (5) developing cost estimates to form the gender budgets and subsequently identifying the budget heads.

Identifying the spatial dimensions of ex-ante gender budgeting is a critical step. The gender issues differ from region to region within a country. For instance, within India, the needs of women in a desert village in Rajasthan may differ from the needs of women in a coastal village in Kerala. The gender concerns of "state of nature" regions in Andaman and the Nicobar Islands differ from the gender issues in the urbanised regions of Haryana with zero forest zones. 
Ex-ante analysis of gender budgeting can extract data from time budgets for spatial mapping of gender specific needs. The patterns emerging from time budgets can give clues as to revealed preferences and demand mechanisms which in turn can be used for the spatial mapping of gender specific needs.

\section{II.3. Tax}

Conceptual discussions of gender budgeting have highlighted the significance of constructing a "care tax" and analyse its co-movement along with other direct and indirect taxes (Elson 2000). Such a project has hardly been attempted across countries. The time use budgets have a significant role in constructing the "care tax." As defined by Elson (2000), a care tax is a notional concept of tax valued on the time spent in care work by men and women. As time budgets are not available across countries, a "care tax" has rarely been constructed or analyzed.

Empirical studies on gender responsive tax policy, in particular gender disaggregated tax incidence, are rare. Tax incidence studies are generally framed in terms of the tax burden across income categories (Pechman, 1985; Engel, Galetovic and Claudio-E, 1999) and not by their gendered incidence. In the context of India, a study on tax incidence across gender has been conducted for West Bengal (Chakraborty P., Chakraborty L., and Karmakar, K., 2008).

In the context of developed countries like Australia, an early campaign focused on the "dependent spouse rebate" paid primarily to male breadwinners, which the Federal Treasury eventually acknowledged in one of the early Federal Women's Budgets was a gender issue (Sawer, M., 2002). In the context of developed countries, more recent work relates to the gender aspects the interaction between the tax and welfare systems in creating higher effective marginal tax rates for women. This has been a major criticism of the family assistance packages of recent federal budgets (Patricia Apps and Ray Rees, 2008). Apps and Rees (2008) argued that the recent reforms in the US, UK and Australia with lower tax rates on high incomes and expanded tax credits and family transfer payments that are withdrawn on the joint income of a couple have led to high effective marginal rates across a wide middle band of earnings and to a shift towards joint taxation. They also argued that joint taxation results in high tax rates on secondary earners, resulting in undesirable effects on both work incentives and the fairness of the income distribution. The lifecycle analysis of time use and saving decisions applied in the study indicated strong negative effects on female labor supply and household saving. 


\section{TIME BUDGETS IN THE EMPIRICAL DESCRIPTION OF GENDER-SPECIFIC OUTCOMES}

The empirical description of gender-specific outcomes is a basic premise for any gender budgeting policy. Until 2010, the single most significant index used for identifying the genderspecific outcomes of any nation was the Gender Development Index (GDI). This global index neutralizes or does not utilize many of the nation-specific gender inequality issues. For instance, the gender disaggregated income component of GDI is constructed on the basis of market economy statistics. But, as is well known, women often work in non-market sectors and the nature of the economic activity performed by women is very often of an unpaid or unremunerated nature. Unless GDI is corrected for this component by incorporating the time budgets, GDI remains partial in its construction.

The Gender Development Index was a version of Human Development Index, but it adjusts for the degree of disparity in achievement across genders using "equally distributed equivalent achievements." The equally distributed equivalent achievement for a variable is taken as that level of achievement that if attained equally by women and men would be judged to be exactly as valuable socially as the actually observed disparate achievements (Anand and Sen, 1995). Taking an additively separable, symmetric, and constant elasticity marginal valuation function with an elasticity of 2 , the equally distributed equivalent achievement $\mathrm{X}_{\text {ede }}$ for any variable $\mathrm{X}$ turns out to be:

$X_{\text {ede }}=\left[n_{f}\left(1 / X_{f}\right)+n_{m}\left(1 / X_{m}\right)\right]^{-1}$

where $X_{f}$ and $X_{m}$ are the values of the variable for females and males, and $n_{f}$ and $n_{m}$ are the population shares of females and males. $\mathrm{X}_{\text {ede }}$ is a "gender-equity-sensitive indicator" (GESI). Thus, for this chosen value of 2 for constant elasticity marginal valuation function, GDI is computed as:

$\left\{\mathrm{L}_{\text {ede }}+\left(2 / 3 \times \mathrm{A}_{\text {ede }}+1 / 3 \times \mathrm{E}_{\text {ede }}\right)+\mathrm{Y}_{\text {ede }}\right\} / 3$

where $\mathrm{L}$ is life expectancy; $\mathrm{A}$ is adult literacy rate; $\mathrm{E}$ is the enrollment ratio; and $\mathrm{Y}$ is income.

If the partial construct of the GDI is used as the optimal criteria for framing gender budgeting policies to analyze the asymmetry in socio-economic scale across gender, the gender budgeting policy itself would reflect the partial status of women with elements of elite capture. 
The income component of GDI is partial as it leaves out unpaid economic activity. It is well-known that unpaid work remains significantly invisible in national accounts. In terms of time budgets, the income of any country captures only a part of economic activity. This categorization of activities used in the time use studies (TUS) in India reveals how partial the GDP of a country is. Time budgets categorize activities into threefold: (1) system of national accounts (SNA) activities (that get included in GDP calculations), (2) extended SNA activities (that do not get included in GDP but should be included in the satellite accounts) and (3) residual non-SNA activities.

United Nations Development Programme (UNDP) estimates suggest that US \$16 trillion of global output is invisible and US \$11 trillion was the non-monetised, invisible contribution of women (UNDP, 1995). The attempt of United Nations Statistical Division (UNSD) in extending the production boundary of the System of National Accounts (SNA) in 1993 has led to the integration of unpaid care work into the national accounting system as satellite accounts.

\section{1. Gender Inequality Index}

Since 2010, the Human Development Index and Gender Development Index have undergone changes in terms of the variables used in calculating these indices as well as in the methodology employed. However, time use statistics have not been used to revise the income component of the index. Since 2010, HDI is geometric mean of three dimensions: health, education and income. The normalization procedure for these three dimensions is as follows.

Normalization Procedure:

- $\quad$ Life Expectancy Index $=[($ LE-20) / (82.3-20) $]$

- $\quad$ Education Index $=[($ root of MYSE* EYSI $) / 0.978]$ as per $2001 \mathrm{HDR}$

- MYS: Mean years of schooling (Years that a 25-year-old person or older has spent in schools)

- EYS: Expected years of schooling (Years that a 5-year-old child will spend with his education in his whole life) (Barro and Lee , 2010)

- $\operatorname{INCOME}=[(\ln (\mathrm{Y})-\ln (\mathrm{Ymax}) /(\ln (\mathrm{Ymax})-\ln (\mathrm{Ymin}))[\mathrm{in} \mathrm{pc}]$ 
When it comes to capturing the gender dimensions, health, empowerment, and labor are taken as the prioritized dimensions, where empowerment is captured through education and participation in governance. The variables used for each dimension are as follows:

Health

- Maternal mortality rate (the number of maternal deaths per 1,000 women of reproductive age in the population, generally defined as 15-44 years of age).

- Adolescent fertility rate (the number of births per 1,000 women ages 15-19).

Empowerment

- Education

- Mean years of schooling (Barro and Lee, 2010)

- Governance/Political Participation

Labor market participation.

The labor market participation is captured through the regular statistics, and not through time use in this reformulation of gender index. There is immense potential to improve the index by incorporating workforce participation using time use statistics. The plausibility of incorporating time use in the income component of HDI, to value "hard-to-price" components of GDP was a missed opportunity in the reformulation of HDI in 2010. However, gender budgeting also utilizes the diagnosis from non-composite measures of gender development, where the unpaid care sector needs a cautious treatment using time budgets.

\section{TIME USE IN QUANTIFYING THE UNPAID CARE COMPONENT OF GENDER BUDGETING}

Gender budgeting ideally should consider the aggregate contribution of women and men to the economy, taking into consideration both the market economy and the care economy. However, across countries, the gender budgeting procedure stops with looking at women's contribution to the market economy. The data, for instance for India, show that only a miniscule number of women work in the organised sector, with participation as low as 4 percent. If we consider women's contribution to the economy by only looking at the market economy, the analysis has high a probability of being skewed and also may run the risk of elite capture. Having said this, even the market economy related gender budgeting policies are also partial as they have not come up with any social security related policies for women related to their loss of work time in 
the care economy. An additional point to flag is that a significant part of women's work is invisible and carried out in the care economy. Time use surveys have been an effective tool in unpacking the statistical invisibility of unpaid work across countries.

Using the probability sample of all types of days (weekdays and weekends) and of different seasons of the year, the time diary method provides a retrospective chronological account of recent twenty-four hour periods of the respondent's time use. Researchers then code the responses using a standard list of economic and non-economic activities. Time use diaries are preferred over the other methods because they tend to be more comprehensive; they enable respondents to report activities in their own terms; and they have some built-in checks that increase the reliability of the data (Juster, 1985). However, one of the deficiencies of the time diary method is how it treats the presence of multitasking and its omission of overlapping activities. This results from the imposition of a rigid constraint on time use; namely, no person has either more or less time available than 24 hours per day (time constraint) and the set of activities that can be measured, described, and analysed must add up to a fixed number of hours or days (Floro, 1995).

Two challenges can be encountered while estimating the value of unpaid care work. One challenge is to get the economic activity in utils (i.e., units utilized) of time. The second challenge is to impute the market price or market wages to time. Imputing price to time is an output method of valuing unpaid care, while imputing wages to time spent on unpaid care is an input method. The input method is complicated in terms of the wage we select for the analysis, specifically whether it is a global substitute, specialized substitute, or an opportunity cost. The global substitute method is relatively easy, as it can use the lowest wage in the wage hierarchy of the market economy, though this results in underestimates. The preferred method is to use a specialised wage as it uses the wages of a specialised worker who would perform each specific economic activity. Using opportunity cost is important as it is based on a wage, which the person carrying out the domestic work would receive if she/he worked in the market. This approach can result in the widest range of estimates, depending on the skills and the opportunity cost of the wage of the individuals performing the work (Beneria, 1992). From the perspective of integrating care for gender budgeting, input-related accounting is superior to output-related accounting as it can capture the intensified effort. 


\section{GENDER DIFFERENTIAL IMPACTS OF PUBLIC SPENDING: TIME USE METHODOLOGY}

Gender budgeting usually examines only programs that specifically target women, which is only around one per cent of the total budget. The challenging part of any gender budgeting exercise is to analyze mainstream expenditures through a gender lens. The partitioning gender factor for mainstream public expenditures is rarely available. The data related to enrollment are used as the partition factor for education budgets, while morbidity statistics are used as the partition factor for analyzing the distributional impact of health budgets. It is difficult to analyze mainstream budgets in terms of their gender differential impacts (other than education and health) due to unavailability of "unit utilized" data. Time use budgets are very helpful in providing unit utilized data especially for water and energy budgets. Time budgets can also provide clues for framing "care economy" policies as well. Methodologically, the differential incidence across gender of public spending can be captured through unit costs and time utils. This utils in time is especially relevant when data on units utilized are generally unavailable, especially for mainstream public spending like water and fuel. The effectiveness of public spending across gender or public expenditure using time incidence is estimated by the following formula:

$$
\begin{aligned}
& \mathrm{I}_{\mathrm{j}} \equiv \sum_{\mathrm{i}} \mathrm{T}_{\mathrm{ij}}\left(\mathrm{E}_{\mathrm{i}} / \mathrm{T}_{\mathrm{i}}\right) \\
& \equiv \sum_{\mathrm{i}}\left(\mathrm{T}_{\mathrm{ij}} / \mathrm{T}_{\mathrm{i}}\right) \mathrm{E}_{\mathrm{i}} \\
& \equiv \sum_{\mathrm{i}} \mathrm{t}_{\mathrm{ij}} \mathrm{E}_{\mathrm{i}}
\end{aligned}
$$

where $\mathrm{Ij}=$ time specific incidence on category $\mathrm{j}$;

$\mathrm{T}_{\mathrm{ij}}=$ time utilization of provision $\mathrm{i}$ by category $\mathrm{j}$;

$\mathrm{E}_{\mathrm{i}}=$ public spending (net) on provision $\mathrm{i}$; and

$\mathrm{t}_{\mathrm{ij}}=$ time utilisation of category $\mathrm{j}$ of performing provision $\mathrm{i}$.

The estimates of time incidence need to be interpreted with caution. For instance, high incidence estimates for women and girls from public provisioning of certain infrastructure services like water and fuel point to high utilization, primarily because women and girls are responsible for ensuring that there is clean water and sufficient fuel for households. These time incidence estimates have policy implications, as a deficiency in certain types of infrastructure investment can increase the intensity of time spent to ensure that these services are provided for 
a household. $\mathrm{T}_{\mathrm{ij}}$ needs to be estimated separately for public provisioning of the service and nonpublic provisioning of the service. Non-public provisioning could also incorporate the utilization of common property resources. This is an illustrative methodology of time incidence, which needs refinement in terms of unit cost and time categories. The time incidence approach also suffers from the same methodological deficiencies of benefit incidence analysis.

\section{CONCLUSION}

An empirical description of gender-specific outcomes is the prelude to gender budgeting. However, time has not been incorporated in the analysis either at the gender diagnostic levels or incidence levels. If budgeting through a gender lens is predominantly based on the index-based, empirical description of gender-specific outcomes, a reexamination of the construction of the gender (inequality) index is urgently needed. This is a significant step necessary to avoid an incomplete capture of the gender-specific impacts of fiscal policies. From a public finance perspective, the conduct of gender budgeting often rests on the assumption that mainstream expenditure, such as public infrastructure, is non-rival and non-excludable in nature and applying gender lens to these expenditures is not feasible. This argument is refuted by the time budget statistics. The time budget data revealed that this argument is often flawed, as there is an intrinsic gender dimension to non-rival expenditures. The time incidence analysis can provide estimates supporting greater time allocation in economic activities like fetching water and fuel which typically involve more girls and women, and therefore public infrastructure investment with gender sensitive water polices and energy policies can truly benefit women and girls. The methodology suggested above is illustrative and suffers from same methodological deficiencies as benefit incidence analysis. 


\section{REFERENCES}

Anand, S., and Sen, A. (1995) 'Gender Inequality in Human Development: Theories and Measurement', Human Development Report Office Occasional Paper 19. New York: United Nations Development Programme.

. (2000): 'The Income Component of the Human Development Index', Journal of Human Development, Vol. 1, No. 1, pp. 83-106.

Apps, P., and Rees, R. (2008) Taxation, Labour Supply and Saving Discussion paper by for the ANU Centre for Economic Policy Research, Canberra.

Barro, R., and Lee, J. (2010) A New Data Set of Educational Attainment in the World, 19502010, NBER Working Paper 15902, NBER.

Becker, G. (1965) “A Theory of the Allocation of Time.” The Economic Journal, Vol. 75, No. 299. (Sep., 1965), pp. 493-517

Beneria, L., and Feldman, S., (1992) Unequal Burden: Economic Crises, Persistent Poverty, and Women's Work (eds.), Westview Press, Boulder, CO.

Chakraborty, P., Chakraborty, L. and Karmakar, K. (2008), Gender and Incidence of Indirect Tax in India, mimeo, New Delhi: National Institute of Public Finance and Policy.

Chakraborty, L. S., and Bagchi, A. (2007), Fiscal Decentralisation and Gender Responsive Budgeting In South Africa: An Appraisal, Working Paper 44, New Delhi: National Institute of Public Finance and Policy.

Chakraborty, L. S. (2002), Gender Budgeting in Sri Lanka: Categorising Financial Inputs. UNIFEM and the Government of Sri Lanka.

. (2003), Gender Based Analysis (GBA) in Canada: Lessons for India. Paper prepared under DFAIT Government of Canada SICI Fellowship, Ottawa.

. (2003a), Macroscan of Union Budget through a Gender Lens. New Delhi: UNIFEM.

. (2004), Gender Budgeting in Asia: An Empirical Investigation of Selected Seven Countries. London: The Commonwealth Secretariat.

. (2005), 'Public Policy Stance and Human Development: An Empirical Analysis', in Bhattacharyya, B. B., and Mitra, A. (eds.) (2005), Macroeconomics and Welfare. New Delhi: Academic Publishers.

. (2005a), Gender Budgeting in Selected Ministries: Conceptual and Methodological Issues, Working Paper, May. Ministry of HRD, Government of India. 
. (2006), 'Fiscal Decentralisation and Local Level Gender Responsive Budgeting In Philippines: An Empirical Analysis,' Working Paper No. 41. New Delhi: National Institute of Public Finance and Policy.

. (2006a), 'Ex-post Gender Sensitive Analysis of Union Budget 2006-07, Government of India', NIPFP, UNIFEM.

. (2007a), "Public Infrastructure Investment and Non-market Work in India: Selective Evidence from Time Use Data." Working Paper No. 47. New Delhi: National Institute of Public Finance and Policy (NIPFP).

. (2007b), “Gender Responsive Budgeting and Fiscal Decentralization in India: A Preliminary Appraisal.” Working Paper No. 46. New Delhi: National Institute of Public Finance and Policy (NIPFP).

- (2008) Deficient Public Infrastructure and Private Costs: Evidence for Water Sector, Economic and Political Weekly, July 2008 and also appeared as a Levy Economics Institute Working Paper, Levy Economics Institute of Bard College, Annandale-onHudson, New York.

. (2009), Fiscal Decentralization and Gender Budgeting in Mexico: An Empirical Analysis, Regional Development Studies, United Nations Center for Regional Development (UNCRD), Vol. 12.

. (2010), 'Public Investment and Unpaid Work: Selective Evidence from Time-Use Data. In R. Antonopoulos and I. Hirway (eds.), Unpaid Work and the Economy: Gender, Time-Use and Poverty. New York: Palgrave Macmillan.

. (2010a), Gender Sensitive Fiscal Policies: Experience of ex-post and ex-ante Gender Budgets in Asia Pacific, background paper prepared for UN Human Development Report 2010, Bangkok: UNDP.

. (2011), Determining Gender Equity in Fiscal Federalism: Analytical Issues and Empirical Evidence from India, Economics and Financial Markets, Volume 6 (3), Sept. 2011, New York. (also the Working Paper No. 590, 2010, The Levy Economics Institute of Bard College, New York)

Chakraborty, L., Singh, Y., and Jacob, J.F. (2013). Public Expenditure Benefit Incidence in Health Sector, Working Paper 748, Levy Economics Institute of Bard College, Annandale-on-Hudson, New York.

Demery, L., Chao, S., Bemier, R., and Mehra, K. (1995), The Incidence of Social Spending in Ghana, Poverty and Social Policy Discussion Paper, 82, Washington DC: World Bank.

Demery, L. (2000) 'Benefit incidence: a practitioner's guide.' Poverty and Social Development. Group, The World Bank (mimeo), Washington, DC: World Bank. 
Elson, D. (1999): Tools for GRB, Commonwealth Secretariat, 1999, London . (1999a), Gender Budget Initiative: Background Papers. London: Commonwealth Secretariat.

. (1995) "Gender Awareness in Modeling Structural Adjustment", World Development, Vol.23, No.11, pp.1851-1868.

Elson, D., and Cagatay, N. (2000), 'The Social Content of Macropolicies', World Development, Vol.28, No.7, pp.1347-1364.

Engel,-Eduardo-M-R-A; Galetovic,-Alexander; Raddatz,-Claudio-E (1999), “Taxes and Income Distribution in Chile: Some Unpleasant Redistributive Arithmetic" Journal of Development Economics, June 1999; 59(1): 155-92.

Esim, S. (2002), "Gender Analysis of Budgets as a Tool for Achieving Gender Equality in the Arab World", Economic Research Forum Newsletter, 9(2), Summer.

Fan, S., Hazell, P., Thorat, S. 1999, Growth, and Poverty in Rural India, IFPRI Research Report, Washington, DC.

Floro, M. S. (1995): 'Economic Restructuring, Gender and the Allocation of Time', World Development, Vol.23, No.11, pp.1913-1929.

Juster, F. T., and Stanford, F. (1991): 'The allocation of time: Empirical Findings, Behavioral Models and Problems of Measurement', Journal of Economic Literature, 29 (), 471-522.

Lahiri, A., Chakraborty, L., and Bhattacharrya (2000), 'India-Gender Budgeting', Report submitted to UNIFEM, South Asia, and Ministry of Human Resource Development, Government of India.

. (2001), 'Gender Budgeting in India: Post Budget Assessment Report 2001', Report submitted to UNIFEM, South Asia and Ministry of Human Resource Development, Government of India.

. (2002a), 'Gender Budgeting in India', Report submitted to UNIFEM, South Asia and Ministry of Human Resource Development, Government of India.

. (2002b), 'Gender Diagnosis and Budgeting in India,' Report submitted to UNIFEM, South Asia and Ministry of Human Resource Development, Government of India. . (2003), 'Gender Budgeting in India', UNIFEM, South Asia.

Pechman, J. A. (1985) Who Paid the Taxes - 1966-85?, Brookings Institution, Washington DC. 
Rao M.G., and Chakraborty, L.S. (2006), "Fiscal Decentralisation and Local Level Gender Responsive Budgeting in Morocco: Some Observations", Working Papers id:771, eSocialSciences.

Sawer, M. (2002) Australia: The Mandarin Approach to Gender Budgets. Gender Budget Make More Cents: Country Studies and Good Practice. D. Budlender and G. Hewitt, Commonwealth Secretariat, London.

Stotsky, J. (2006) Gender Budgeting, IMF Working Paper, Washington DC.

United Nations Statistical Division (1993) Systems of National Accounts 1993, United Nations, New York.

United Nations Development Programme (1995) “Human Development Report”, Oxford University Press, New York . (2011), Asia-Pacific Human Development Report 2011, UNDP.

UN Women (2012), Gender Budgeting: Evaluation Report, New Delhi. 